\title{
Experimental investigation of surface roughness effect on fatigue performance of AISI 1045 carbon steel and fatigue limit prediction
}

\author{
Khadija Kimakh, Abdelkerim Chouaf, Amal Saoud, El Hassan Mallil \\ Hassan II University, National Superior School of Electricity and Mechanics Casablanca (ENSEM), LCCMMS, Morocco. \\ khadija.kimakb@gmail.com, http://orcid.org/0000-0002-2418-1307 \\ a.chouaf.ensem@gmail.com, bttp://orcid.org/ \\ Saoudamal22@gmail.com bttp://orcid.org/0000-0002-2139-2627
}

Samir Aghzer

Hassan II University, Superior School of Technology Casablanca (EST), LCCMMS, Morocco.

\begin{abstract}
.
In fatigue life, surface integrity perform a major role to determine the fatigue lifetime. It could differ greatly among specific cases even for the same solicitations. Indeed, the manufacturing process carries modifications on surface state, residual stresses and the microstructure which affects the fatigue behavior of mechanical parts.

This article investigate the effect of surface roughness on the fatigue strength of AISI 1045 carbon steel obtained by the turning process.

The work carried out consists in testing in uniaxial fatigue different batches of specimens which have a controlled surface state. The S-N curves obtained present a strong dependence between fatigue performance and surface state. Based on the surface topography, a model for predicting fatigue limit will be adopted.
\end{abstract}

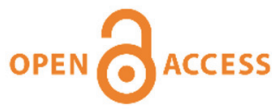

Citation: Kimakh, K., Chouaf, A., Saoud, A., Mallil, E.-H., Aghzer, S., Experimental investigation of surface roughness effect on fatigue performance of AISI 1045 carbon steel and fatigue limit prediction, Frattura ed Integrità Strutturale, 48 (2019) 429-441.

Received: 21.12.2018

Accepted: 22.02.2019

Published: 01.04.2019

Copyright: (C) 2019 This is an open access article under the terms of the CC-BY 4.0, which permits unrestricted use, distribution, and reproduction in any medium, provided the original author and source are credited.

KEYWORDS. Fatigue; Surface roughness; Turning condition; Fatigue limit.

\section{INTRODUCTION}

7 he fatigue behavior of materials is a major issue which interest the designers and manufacturers. Their main motivation is to obtain components with a low cost and a long fatigue life time, the latter is affected by many parameters. The manufacturing process is one of the influencing factors. Indeed, it generates modifications on the surface integrity, namely the microstructure, the residual stresses and the surface state.

Therefore several researchers have been interested to study the influence of surface integrity on fatigue behavior. They showed that all the cutting parameters affect significantly the results obtained during a machining operation. This generates changes in surface integrity and consequently fatigue behavior $[1,2]$.

Based on different analytical or experimental models, several studies have highlighted the impact of topography and surface integrity on fatigue behavior of materials. Unfortunately, these models don't consider all influencing factors. 
Zhang and al [3] studied the fatigue behavior of FV520B-I steel for different surface roughness $(\mathrm{Ra}=0.6 \mu \mathrm{m}, \mathrm{Ra}=0.2 \mu \mathrm{m}$ and $\mathrm{Ra}=0.05 \mu \mathrm{m})$. For smooth specimens crack initiate from subsurface for the majority of specimens except for very high stresses, the cracks initiate from the surface. However, for rough specimens the stress concentrations are very important which promote the crack propagation. In fact, the fatigue lifetime decrease considerably.

Surmarchai and al [4] analyzed the influence of surface condition on the fatigue lifetime of 7010 aluminum alloy tested in 4-point flexion. They explain the strong dependence between the surface condition and the fatigue propriety. Indeed, roughness streaks generate stress concentrations. Based on this phenomenon, a model of fatigue lifetime prediction has been proposed. For the residual stresses, they have the most predominant influence when the surface state varies between $2.5 \mu \mathrm{m}$ and $5 \mu \mathrm{m}$.

Guolian Liu et al [5] discussed the impact of milling cutting conditions on surface integrity and fatigue strength. The parameters studied are the cutting speed, the feed rate and the depth of cut. Three groups of test specimen were machined. For each group a single parameter were varied over five levels. They confirmed that the cutting conditions affect significantly the surface integrity, therefore the fatigue strength is affected too. It decreases with the increase of cutting speed. For a feed rate less than $0.1 \mathrm{~mm} / \mathrm{rev}$, the lifetime increases with the increase of feed rate. For a feed rate between $0.1 \mathrm{and} 0.2 \mathrm{~mm} / \mathrm{rev}$ the fatigue life increases but beyond $0.2 \mathrm{~mm} / \mathrm{rev}$, it decreases with the fast increasing of residual stresses.

Indeed, the fatigue lifetime of the machined parts depends on the interaction between the different physical parameters involved.

In 2005 Marbu and al [6] investigate the influence of surface state on fatigue behavior of aluminum alloy (7010-T74511). They developed a mechanical model to establish the physical origin of this influence.

Alang [7] studied the effect of surface state on fatigue strength. The roughness was varied over three levels $(1.77 \mu \mathrm{m}, 2.88$ $\mu \mathrm{m}$ and $5.48 \mu \mathrm{m})$ and the specimens were tested for rotating bending. He notes that for lifetimes less than $10^{5}$ cycles, the surface roughness considered didn't present a significant effect, but beyond $10^{5}$ cycles, the specimens with a smooth specimens have a longer lifetime than the rough test specimens.

Youngsik Choi and Khadija Kimakh and al [8,9] analyzed the impact of feed rate on fatigue strength of the machined surfaces of steel. He concluded that the manufacturing process directly affects the microstructure, surface state and residual stresses. The modifications generated on surface or subsurface influence the fatigue behavior of the steel studied.

Several studies didn't establish correlations between cutting parameters and fatigue lifetime of mechanical parts. Few researchers are interested to this problem. Unfortunately, in their studies, the number of parameters has often been limited given the complexity of the problem $[10,11]$.

The aim of our study is to analyze the fatigue behavior of AISI 1045 carbon steel and to predict the fatigue limit for different surface roughness. But the most interesting is to propose a model that allows to have a mastered surface state from a chosen cutting parameters to generate mechanical parts with a better fatigue resistance.

For this purpose, four batches of AISI 1045 carbon steel fatigue test specimens were machined with different cutting parameters generating different surface roughnesses. They were tested in uniaxial fatigue with a stress ratio of $R=0.1$. The results obtained were presented as an $\mathrm{S}-\mathrm{N}$ curves and the fracture surface were observed using a scanning electron microscope SEM. From these results the effect of the roughness on the fatigue lifetime has been demonstrated and Based on roughness profiles and an appropriate models the fatigue limit has been predicted.

\section{EXPERIMENTAL PROCEDURES}

\section{Material}

7 he chemical composition was identified for different samples by spectrometric analysis. Tab. 1 summarizes the chemical composition of the AISI 1045 steel considered for our study.

\begin{tabular}{ccccccccc}
\hline Steel & \multicolumn{7}{c}{ Chemical composition (\%) } \\
AISI 1045 & $\mathrm{C}$ & $\mathrm{Mn}$ & $\mathrm{S}$ & $\mathrm{P}$ & $\mathrm{Si}$ & $\mathrm{Cr}$ & $\mathrm{Ni}$ & $\mathrm{Cu}$ \\
& 0.42 & 0.72 & 0.02 & 0.04 & 0.19 & 0.09 & 0.11 & 0.17 \\
\hline
\end{tabular}

Table 1: Chemical composition of the AISI 1045 steel.

In order to determine the mechanical proprieties of the AISI 1045, tensile tests were carried out according to the ASTM E8 / E8M-13a [12]. Also hardness measurements were performed. Tab. 2 groups the mechanical properties obtained. 


\begin{tabular}{cccccc}
\hline Material & \multicolumn{5}{c}{ Mechanical properties } \\
AISI 1045 & $\mathrm{S}_{\mathrm{y} 02}[\mathrm{MPa}]$ & $\mathrm{S}_{U \mathrm{UTS}}[\mathrm{MPa}]$ & $\mathrm{A} \%$ & $\mathrm{E}[\mathrm{GPa}]$ & $\mathrm{HV}$ \\
& 432 & 650 & 23 & 210 & 185 \\
\hline
\end{tabular}

Table 2: The mechanical properties of AISI 1045 steel.

\section{Specimens and surface preparation}

The geometric characteristics of the specimens considered for fatigue tests were established according to the standard ASTM E466-7 (fatigue test for metallic materials) in Fig. 1 [13].

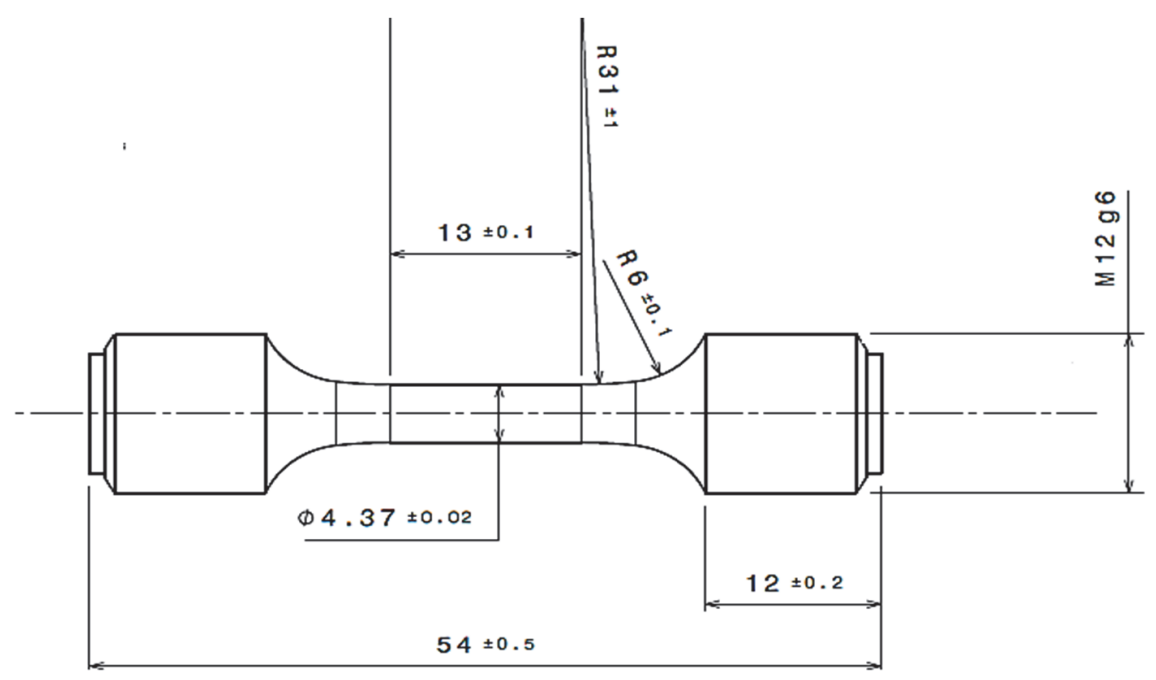

Figure 1: Geometric characteristic of the fatigue specimen (ASTM E466-7).

The fatigue test specimens were machined to obtain four batches with different surface state between $3 \mu \mathrm{m}$ and $0.5 \mu \mathrm{m}$ of roughness. In order to determine the cutting conditions expected to generate specimens with a controlled surface roughness, a mathematical model that expresses the roughness function of cutting conditions was adopted [14]. Tab. 3 summarizes the cutting parameters (spindle speed $\mathrm{N}$, feed rate $\mathrm{f}$, depth of cut ap and tool nose radius $\mathrm{r} \varepsilon$ ) used for the different batches (L1, L2, L3 and L4).

The turning operations were carried out on a CNC lath Alpha 1530XS. Then the specimens were controlled. For the surface state, the roughness were measured using the surface roughness tester of "Mitutoyo" SJ-201M conforming to the standard EN ISO 4288 [15]. For each batch Li, the arithmetical mean height $\mathrm{Ra}$ and the maximum height of the profile Ry values were recorded. The results obtained were presented in Tab. 4.

\begin{tabular}{ccccccccc}
\hline Batches & \multicolumn{3}{c}{ Rough } & \multicolumn{5}{c}{ Finishing } \\
L1 & $\mathrm{N}(\mathrm{rpm})$ & $\mathrm{f}(\mathrm{mm} / \mathrm{rev})$ & $\mathrm{ap}(\mathrm{mm})$ & $\mathrm{r} \varepsilon(\mathrm{mm})$ & $\mathrm{N}(\mathrm{rpm})$ & $\mathrm{f}(\mathrm{mm} / \mathrm{rev})$ & $\mathrm{ap}(\mathrm{mm})$ & $\mathrm{r} \varepsilon(\mathrm{mm})$ \\
$\mathrm{L} 2$ & 1200 & 0.15 & 0.5 & 0.8 & 2500 & 0.25 & 0.5 & 0.8 \\
L3 & 1200 & 0.15 & 0.5 & 0.8 & 2500 & 0.15 & 0.5 & 0.8 \\
L4 & 1200 & 0.15 & 0.5 & 0.8 & 2500 & 0.05 & 0.3 & 0.8 \\
\hline
\end{tabular}

Table 3: Cutting conditions for fatigue specimen machining. 


\begin{tabular}{cccc}
\hline Batches & $\lambda c$ & $\mathrm{Ra}(\mu \mathrm{m})$ & $\mathrm{Ry}(\mu \mathrm{m})$ \\
L1 & 2.5 & 3.125 & 20.71 \\
L2 & 2.5 & 2.263 & 16.55 \\
L3 & 0.8 & 1.242 & 8.65 \\
L4 & 0.8 & 0.5 & 4.03 \\
\hline
\end{tabular}

Table 4: Results of surface roughness measurement

\section{Fatigue test}

The fatigue tests were conducted on a servo-hydraulic machine MTS 810 with a maximum capacity of $100 \mathrm{kN}$. The specimens were tested in uniaxial tension fatigue at stress ratio $\mathrm{R}=0.1$ and a frequency of $40 \mathrm{~Hz}$. All experiments were performed on five different stress amplitude (Tab. 5) at ambient temperature.

\begin{tabular}{cccccc}
\hline Stress & \multicolumn{5}{c}{ Levels } \\
$\mathrm{S}_{\max }[\mathrm{MPa}]$ & 400 & 450 & 500 & 525 & 550 \\
$\mathrm{~S}_{\min }[\mathrm{MPa}]$ & 40 & 45 & 50 & 52.5 & 55 \\
\hline
\end{tabular}

Table 5: Stress levels applied for fatigue tests

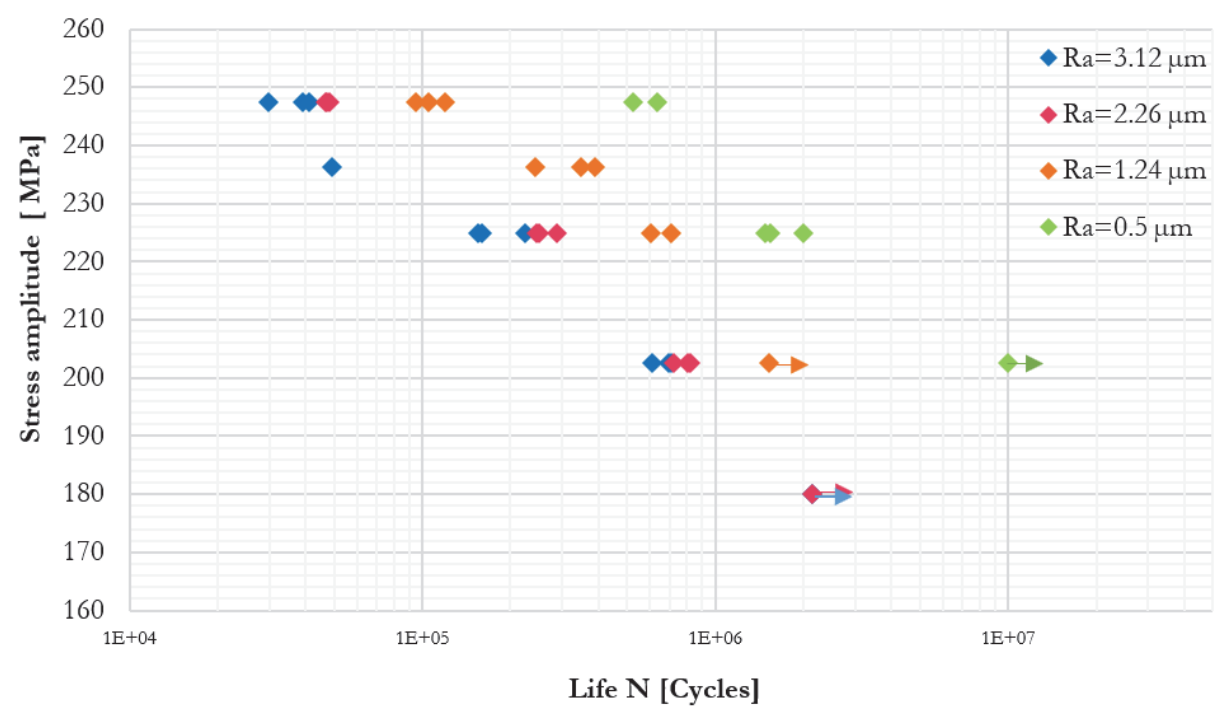

Figure 2: S-N curves of the AISI 1045 steel for different surface state.

\section{RESULTS AND DISCUSSION}

\section{S-N curve for different surface roughnesses}

$\checkmark$ he results obtained from the fatigue tests are represented by the Wöhler curves shown in Fig. 2. These curves were plotted for different surface roughnesses $\mathrm{Ra}(3.12 \mu \mathrm{m}, 2.26 \mu \mathrm{m}, 1.24 \mu \mathrm{m}$ and $0.5 \mu \mathrm{m})$. The differences between these surface state generate shifts between these S-N curves obtained. Indeed, for a stress amplitude of $225 \mathrm{MPa}$, a roughness of $3.12 \mu \mathrm{m}$ ensures a lifetime of $2.10^{5}$ cycles, however a roughness of 1.24 leads to a fatigue lifetime of $6.10^{5}$ cycles. The most marked difference was recorded between $\mathrm{Ra}=3.12 \mu \mathrm{m}$ and $\mathrm{Ra}=0.5 \mu \mathrm{m}$ which corresponds to a considerable gain on lifetime of $9.10^{5}$ cycles. This result confirms that the greater the roughness, the shorter the service life. 
A similar result was obtained by S. Bagehorn [16] in the case of Ti-6Al-4V specimens. According to these results; to reach a lifetime $3.10^{7}$ with a surface roughness of $\mathrm{Ra}=17.9 \mu \mathrm{m}$ a maximum stress of $300 \mathrm{MPa}$ must not exceed. However, with a roughness of $\mathrm{Ra}=0.3 \mu \mathrm{m}$, the maximum stress can go up to $775 \mathrm{MPa}$.

The fatigue lifetime reduction caused by the roughness comes mainly from streaks and scratches presented on the surface. Indeed, it is in term of these surface defects the stress concentration is developed making them as privileged crack initiations sites. Basing on the observation of surfaces specimens and the fractography of fracture surface, the effect of the streaks were highlighted.

From these results (Fig. 2), we can confirm the harmful impact of roughness on fatigue lifetime of mechanical parts. Therefore, it seems important to develop a correlation between roughness and lifetime in order to choose the cutting parameters that ensure a better lifetime.

\section{Fractography of fracture surface}

For three different surface roughnesses, the fractured specimens were observed using a scanning electron microscope (SEM). Fig. 3 present macroscopic surface morphology of specimens observed. Through these fracture surfaces, the three fatigue failure area were observed: the crack initiation, the crack propagation area and the final fracture area.

The fracture surfaces have a matt appearance with a smooth and regular relief at the level of the crack propagation area, while granular at the level of the final fracture area.

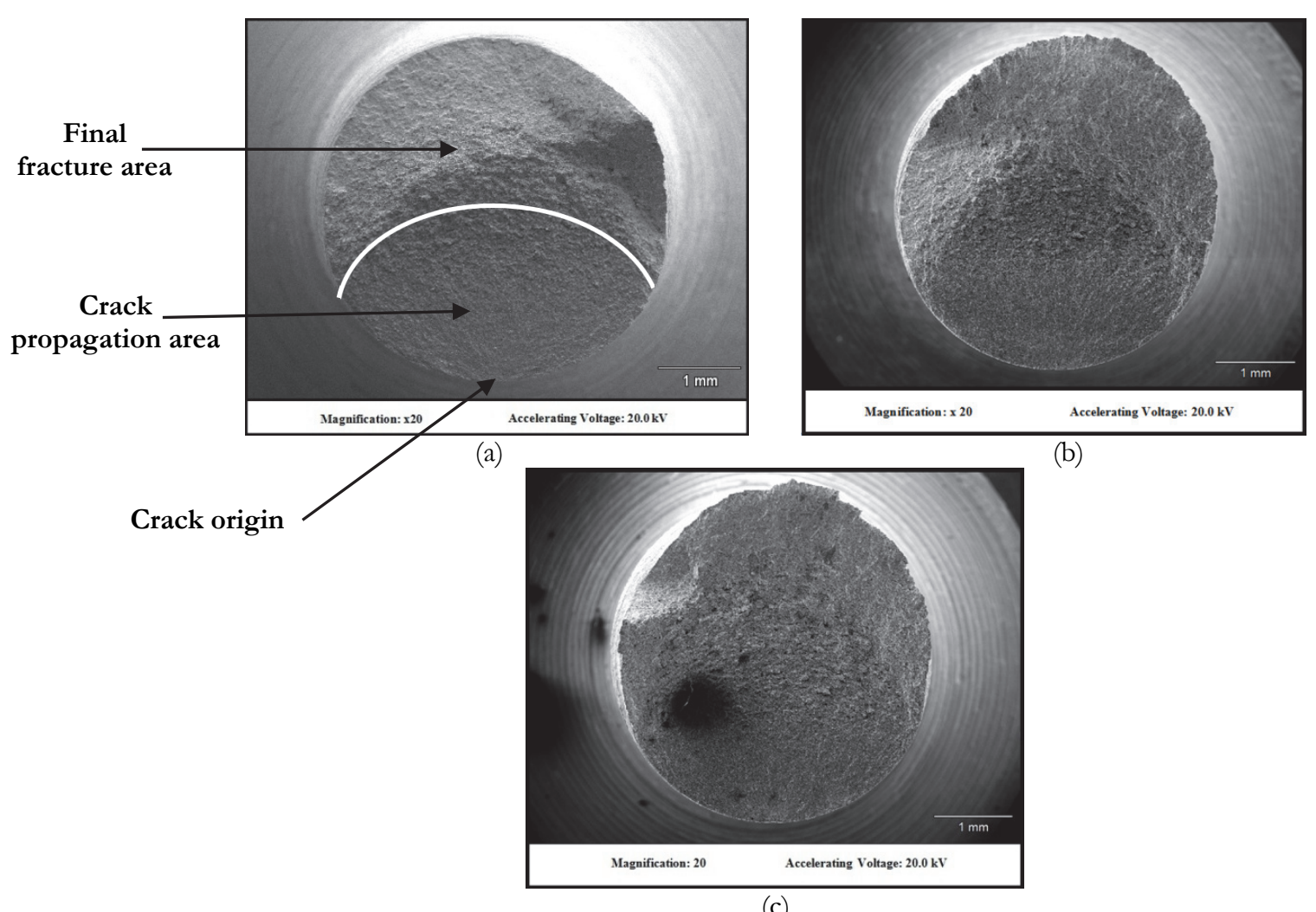

Figure 3: Macrographs of specimen fracture surface morphologies observed in: a) Specimen N6 with surface roughness Ra $=1.24 \mu \mathrm{m}$, b) Specimen N8 with $\mathrm{Ra}=2.26 \mu \mathrm{m}$, c) Specimen N12 with Ra=3.12 $\mu \mathrm{m}$, magnification 20x.

Although the fracture surfaces present macroscopically some similarities, each specimen have its own characteristic. Fig. 5 focus on the crack propagation area and the crack origin.

Fig. 4 presents the image of the specimen surface after turning process. Its surface is covered by curvilinear streak pattern generated by a tool lathe action. The distances between adjacent streaks depend on the turning parameters like cutting rate and tool feed per revolution. The surface streaks and scratches influence on the specimen surface roughness and they are potential spots of crack initiation. The measured average surface roughness of the mentioned specimen was $\operatorname{Ra}=3.12 \mu \mathrm{m}$. Depending on the cutting force used in the process in the bottom of the scratches can develop a deep or shallow crack. 


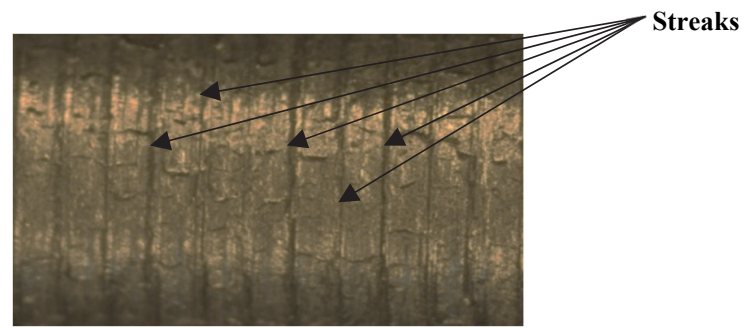

Figure 4: The image of specimen surface morphology after turning process with measured surface roughness $\mathrm{Ra}=3.12 \mu \mathrm{m}$.

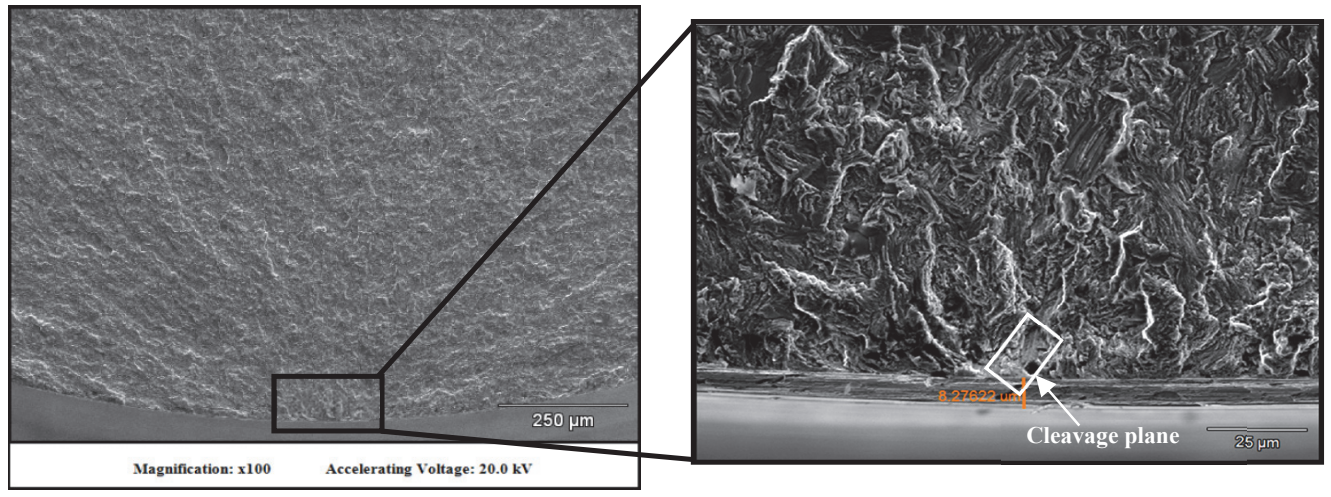

(a)

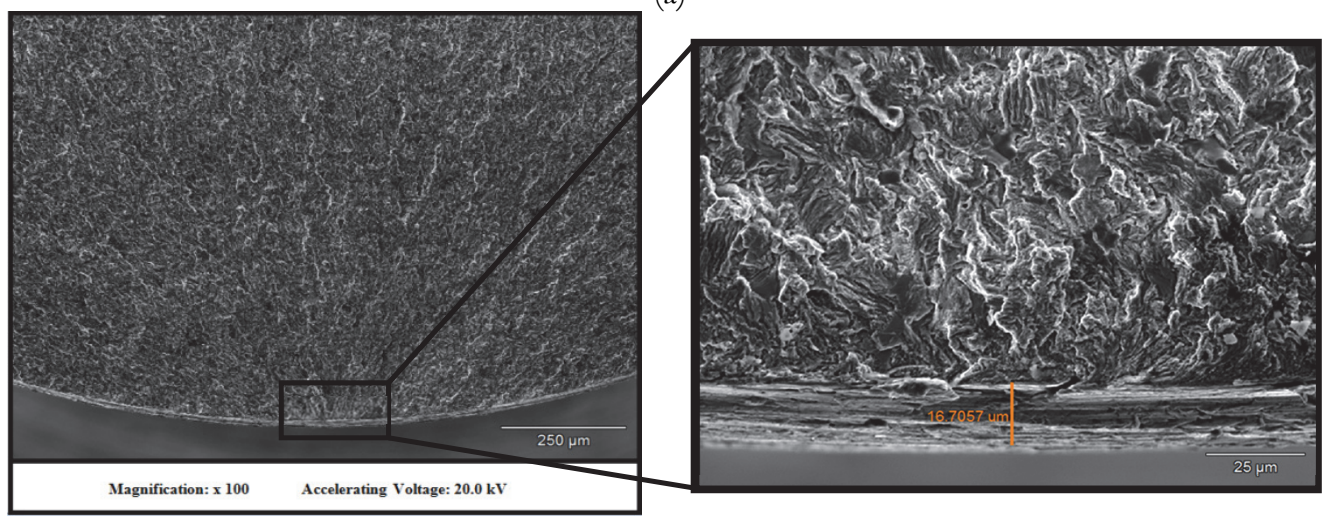

(b)

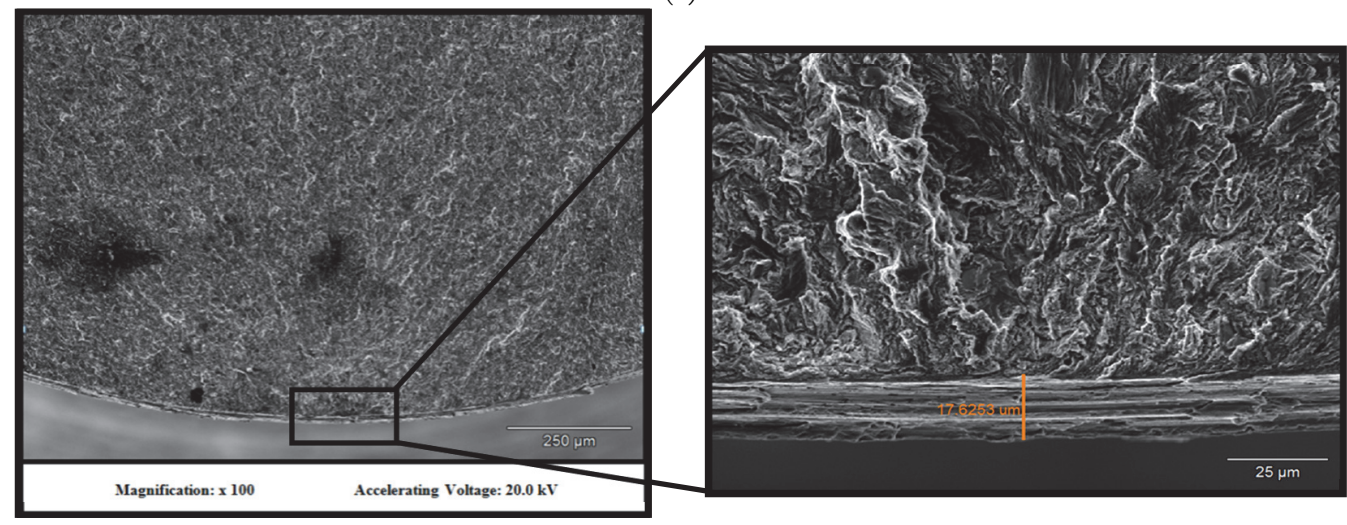

(c)

Figure 5: Macrographs (on the left side) of the fracture surfaces taken from the crack propagation areas and micrographs (on the right side) of the fracture surface areas close the crack initiation spot, respectively, in: Specimen N6 with surface roughness Ra $=1.24 \mu \mathrm{m}$ (a), Specimen N8 with roughness Ra $=2.26 \mu \mathrm{m}$ (b), Specimen N12 with surface roughness $\mathrm{Ra}=3.12 \mu \mathrm{m}$ (c); see text for explanations. 
In our case, the crack propagation area presents ridges in the direction of crack propagation that diverge from the crack origin. In fact, the crack don't initiate from a point, as seen regularly, but it occurs from a curvilinear line. These line can also be observed from the global observations of surface specimens, as shown in Fig. 5. They are in the form of bands depending on the roughness of the specimens. These are scratches generated by the cutting tool. They represent the streaks of roughness.

Fig. 5 focus on crack propagation area and the crack origin. The macrographs on the left sides of the Fig. 5 display the morphologies of the crack propagation areas in three exemplified specimens, as well as the spots of crack initiation situated inside the black frames. These images were taken by using a SEM microscope at the magnification 100x. Mechanism of the steel specimen cracking and crack origin can be analyzed on the basis of the micrographs taken by SEM microscope at higher magnification (800x) and presented on the right sides of Fig. 5. In the case of Specimen Nr 6 its micrograph (a) indicates mainly plastic (ductile) mechanism of material cracking in the form of plastic striations. However, several places on the fracture surface show brittle mechanism of cracking along cleavage planes. This mechanism of cracking is associated with nonmetallic precipitates existed in the AISI 1045 steel. In Specimen $\mathrm{Nr} 6$ crack has been initiated in the spot of a precipitate existed near the bottom of a specimen surface scratch (white frame).

In the case of Specimen Nr 8 the micrograph (b) indicates that the crack developed from a deeper slot made by the tool lathe. This micrograph indicates as well more voids after cracking through the boundaries of the precipitates existed in the steel.

More impurities in the steel material and impurities of greater sizes are observed on the micrograph belong to Specimen $\mathrm{Nr}$ 12. This state of specimen material was confirmed both by its macrograph and the micrograph (c). The crack initiated in a deeper slot made by the tool lathe.

The streaks can be considered as notches generating stress concentrations. Depending on the level of these concentrations, the lifetime of the specimens can be reduced or lengthened [17].

To characterize the fatigue damage of specimens, we measured for the different surface roughness the width of the streak $\left(l_{\text {defect }}\right)$ and the radius of the crack propagation area $\mathbf{r}_{\text {ZPL }}$ (Fig. 6).

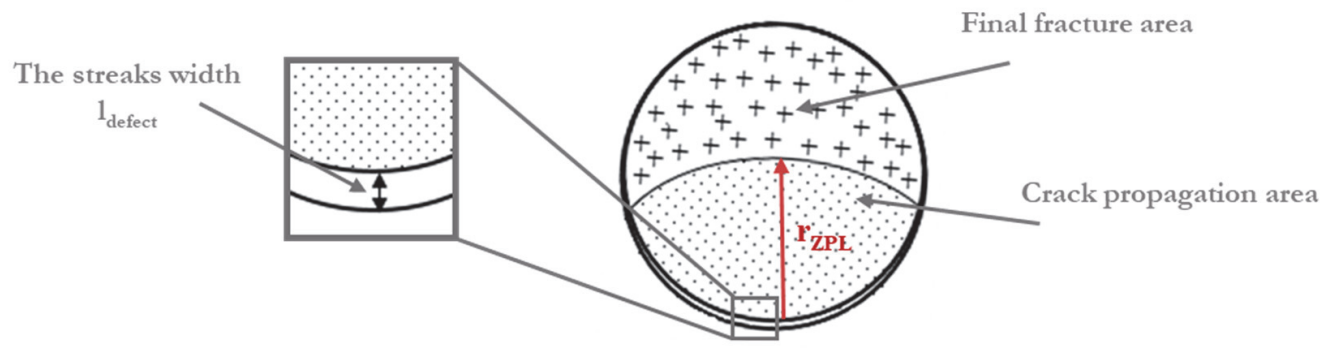

Figure 6: Fracture surface diagram.

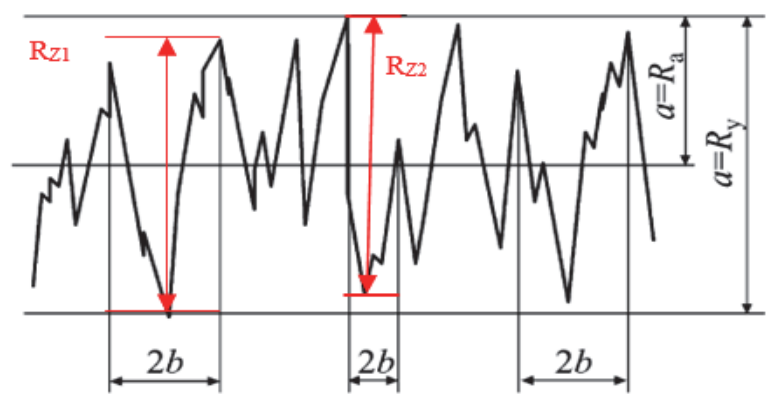

Figure 7: Definition of depth $\mathrm{a}(\mathrm{a}=\mathrm{Ra}$ or $\mathrm{a}=\mathrm{Ry})$ and pitch $2 \mathrm{~b}$ of the roughness profile,

$1_{\text {defect }}$ represents the depth of the surface defect generating the fracture. Tab. 6 groups the values of the streaks width recorded of each surface roughness (Fig. 5). Their values are very closer to those of the total roughness Ry which represents the difference between the highest peak and the deepest valley of the profile. These widths always remain lower to Ry: it is unusual to find a roughness profile where the highest peak $R_{Z 2}$ and the deepest valley $R_{Z 1}$ correspond to the same streak. As shown in Fig. 7, the values of $R_{\mathrm{Z} 1}$ and $R_{\mathrm{Z} 2}$ are always smaller than $\mathrm{Ry}$. Also, we measured the radius of the crack 
propagation area $\mathbf{r}_{\mathbf{Z P L}}$ from fracture surface morphologies Fig. 3. It decreases with the increase of the roughness, thus the crack propagation surface is larger for the low roughness test specimen.

Indeed, with the increase of surface roughness, the width of the streak $1_{\text {defect }}$ increase. However the radius of the crack propagation region rzPL decrease and the number of cycles to failure reduced (Tab. 6).

\begin{tabular}{cccccc}
\hline Specimen & $\mathrm{Ra}(\mu \mathrm{m})$ & $\mathrm{Ry}(\mu \mathrm{m})$ & $\mathrm{l}_{\text {defect }}(\mu \mathrm{m})$ & $\mathrm{r}_{\mathrm{ZPL}}(\mathrm{mm})$ & $\mathrm{N}_{\mathrm{f}}$ (cycles) \\
$\mathrm{N} 12$ & 3.12 & 21.62 & 17.62 & 1.34 & $3.6310^{5}$ \\
$\mathrm{~N} 8$ & 2.26 & 17.23 & 16.71 & 1.42 & $3.7210^{5}$ \\
$\mathrm{~N} 6$ & 1.24 & 8.65 & 7.05 & 1.54 & $6.2210^{5}$ \\
\hline
\end{tabular}

Table 6: Streaks width and radius of the crack propagation region for different surface roughness.

\section{FATIGUE LIFETIME PREDICTION}

\section{Prediction Model}

everal researchers have tried to estimate by different models the fatigue limit of materials in the case of inclusions or S surface defects $[4,17,18]$. In our case, we were interested to Yukitaka Murakami model that established the inclusion area parameter in the surface defect [19].

This model allows the evaluation of the equivalent defect size $\sqrt{\text { area }}$ that present the surface roughness defect, which will provide to predict the fatigue limit $\sigma_{\mathrm{w}}$. According to this study, the equivalent defect size was expressed by the following equation:

$$
\begin{array}{rlrl}
\frac{\sqrt{\text { area }}}{2 b} & =2.97\left(\frac{a}{2 b}\right)-3.51\left(\frac{a}{2 b}\right)^{2}-9.74\left(\frac{a}{2 b}\right)^{3}, & & \frac{a}{2 b} \leq 0.195 \\
\frac{\sqrt{\text { area }}}{2 b} & \approx 0.38, & \frac{a}{2 b}>0.195
\end{array}
$$

The Geometric parameters a and $2 \mathrm{~b}$ were determined from the roughness profile as shown in Fig. 7.

Based on the equivalent defect size, Murakami proposed a model to predict the fatigue limit $\sigma_{\mathrm{w}}$ [MPa] by the following relation:

$$
\sigma_{w}=\frac{1.43(H V+120)}{(\sqrt{\text { area }})^{1 / 6}} \cdot\left(\frac{1-R}{2}\right)^{\alpha}
$$

with

$$
\begin{aligned}
& \alpha=0.226+H V^{* 10^{-4}} \\
& \mathrm{R}=\frac{S_{\text {min }}}{S_{\text {max }}}
\end{aligned}
$$

$\mathrm{HV}$ : vickers hardness $\left[\mathrm{kgf} / \mathrm{mm}^{2}\right]$. 
where $\sqrt{\text { area }}$ is the equivalent default size in $\mu \mathrm{m}, \alpha$ is a parameter that depends on the material function of the Vickers hardness and $\mathrm{R}$ is the stress ratio.

\section{Equivalent defect size from surface roughness profile}

In our case, the formulation proposed were considered to predict the fatigue limit of our material as a function of the surface roughness generated by the chosen cutting conditions. To evaluate the equivalent defect size, we considered the real profiles of specimens observed by an optical microscope instead of the roughness profiles obtained by the surface roughness tester. Actually, the samples were cutted longitudinally to highlight the surface roughness profile. So they were polished to eliminate the traces generated by the cut-off machines. Fig. 7 shows the surface state profiles observed by optical microscope of different surface roughness with two different magnifications (x100 and x200).
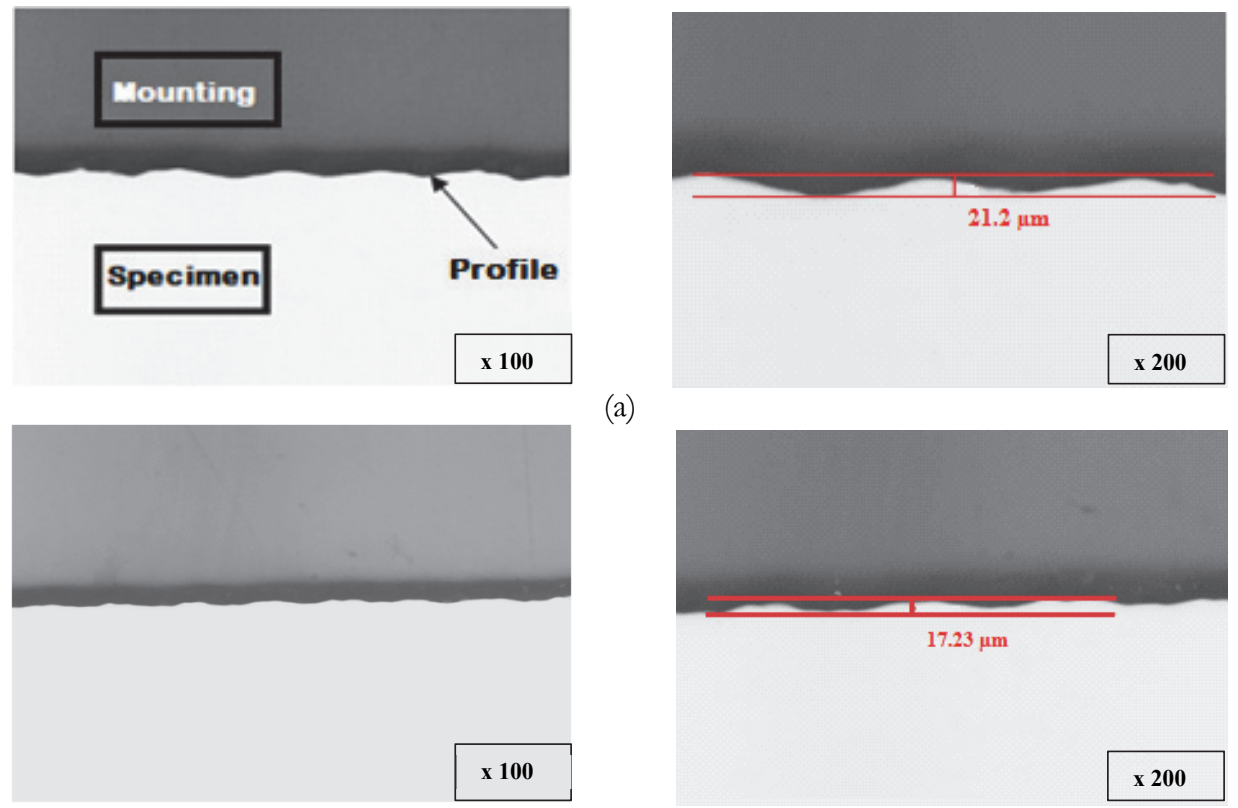

(a)
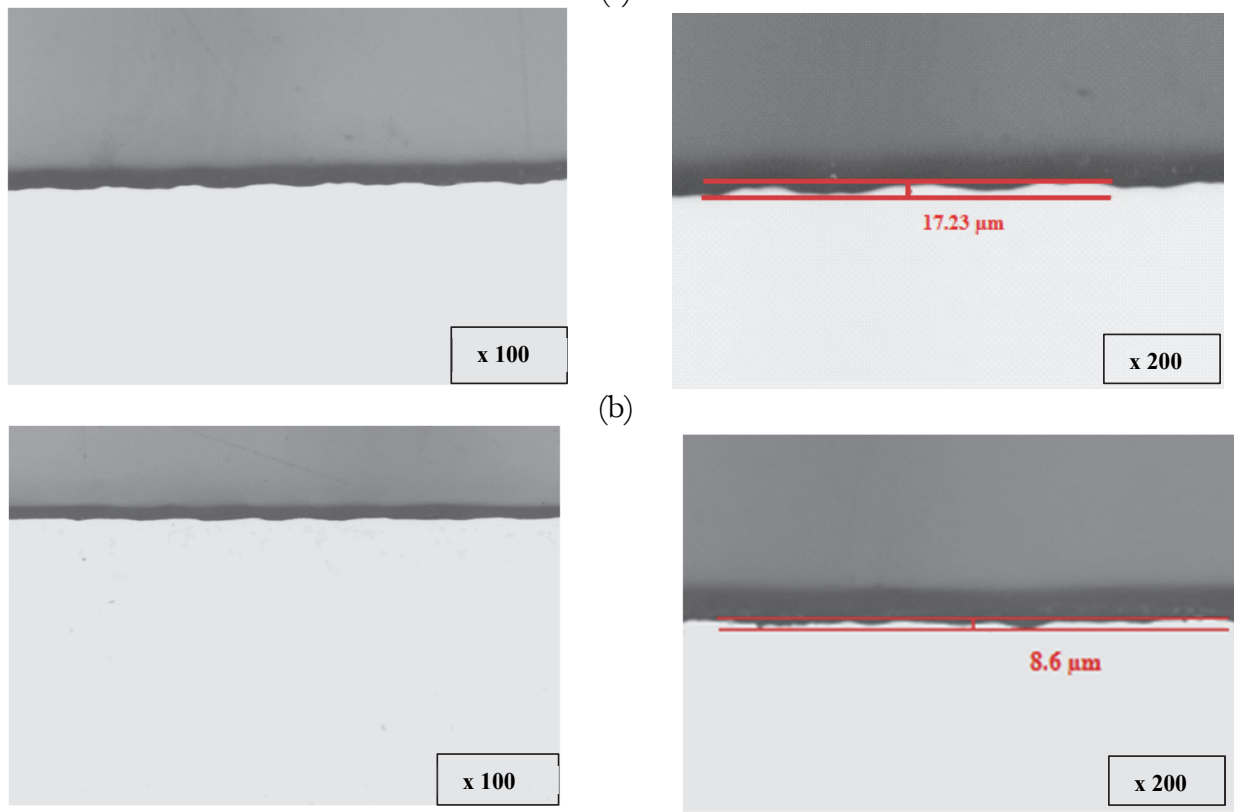

(b)
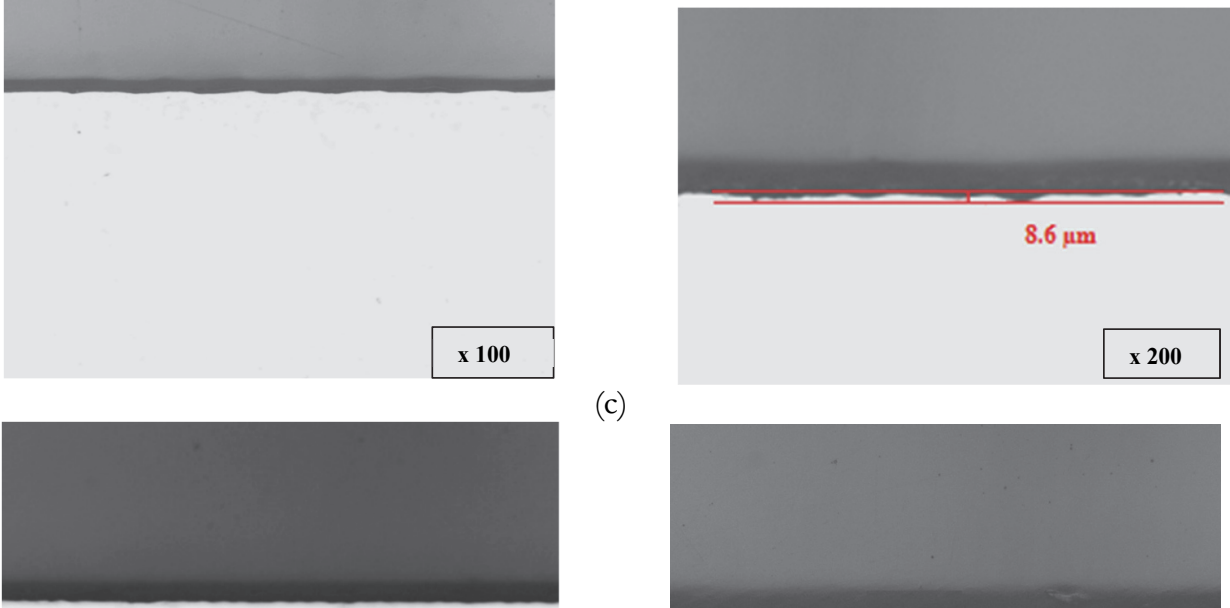

(c)

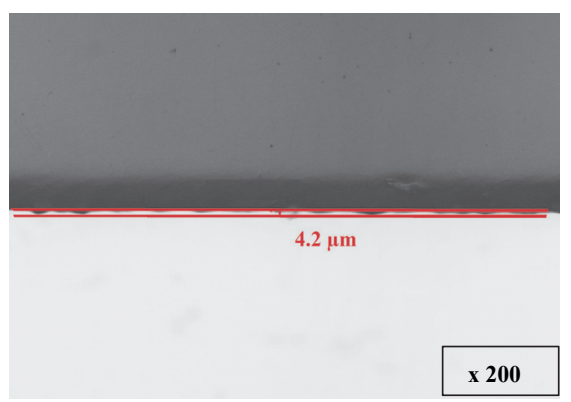

(d)

Figure 8: Roughness profile observations. (a) Specimen with $\mathrm{Ra}=3.12 \mu \mathrm{m}$, (b) Specimen with $\mathrm{Ra}=2.26 \mu \mathrm{m}$, (c) Specimen with $\mathrm{Ra}=1.24 \mu \mathrm{m}$ and $(\mathrm{d})$ Specimen with $\mathrm{Ra}=0.5 \mu \mathrm{m}$. 
These observed profiles (Fig. 8) illustrate geometric irregularities that occur periodically at constant steps. However, their depth varies for the different roughnesses. In fact, these irregularities represent the mark of the cutting tool, they are considered as surface defects which generate stress concentrations. They are likely to decrease the crack initiation and consequently decrease the fatigue lifetime.

From these observations, we have therefore measured the height of the profile that represent the total roughness Ry. The values recorded are very close to the values measured by the surface roughness tester.

The table below shows the data determined from the profile observations ( $\mathrm{a}, 2 \mathrm{~b}$ and the equivalent defect size $\sqrt{ }$ area).

\begin{tabular}{cccccc}
\hline & & \multicolumn{2}{c}{$\mathrm{a} / 2 \mathrm{~b}$} & \multicolumn{2}{c}{$\sqrt{\text { area }}(\mu \mathrm{m})$} \\
batches & $2 \mathrm{~b}(\mu \mathrm{m})$ & $\mathrm{Ra}$ & $\mathrm{Ry}$ & $\mathrm{Ra}$ & $\mathrm{Ry}$ \\
$\mathrm{L} 1$ & 212 & 0.01 & 0.10 & 0.10 & 0.01 \\
$\mathrm{~L} 2$ & 136.88 & 0.01 & 0.12 & 0.12 & 0.01 \\
L3 & 64.32 & 0.01 & 0.12 & 0.12 & 0.01 \\
L4 & 28.91 & 0.01 & 0.14 & 0.14 & 0.01 \\
\hline
\end{tabular}

Table 7: Equivalent defect size for the different surface roughnesses.

\section{Result and discussion}

From the measurement of the geometrical parameters and the evaluation of the roughness equivalent defect size, the fatigue limit were predicted for each surface roughness. It can be estimated as a function of Ra or Ry.

\begin{tabular}{ccccccc}
\hline & & \multicolumn{2}{c}{$\sigma_{\mathrm{w}}$ (predicted) $[\mathrm{MPa}]$} & $\sigma_{\mathrm{w}}(\exp )[\mathrm{MPa}]$ & \multicolumn{2}{c}{ Gap } \\
Batches & $\mathrm{Ra}(\mu \mathrm{m})$ & Function of Ra & Function of Ry & & Ra & Ry \\
& & 150 & 112 & 180 & 30 & 68 \\
L1 & 3.125 & 112 & 183 & 24 & 65 \\
L2 & 2.263 & 159 & 133 & 196 & 20 & 63 \\
L3 & 1.242 & 176 & 149 & 202.5 & 1.5 & 53.5 \\
L4 & 0.5 & 204 & & & \\
\hline
\end{tabular}

Table 8: Comparisons of Predicted and Experimental Fatigue Limit Values for Different Roughness Studied

The results obtained for the fatigue limit prediction revel the effect of surface roughness. In fact the fatigue limit increase with the decrease of the surface roughness in the two cases where $\mathrm{a}=\mathrm{Ra}$ or $\mathrm{a}=\mathrm{Ry}$.

On one hand the difference between the fatigue limit obtained experimentally and that predicted is reduced when we consider $\mathrm{a}=\mathrm{Ra}$. This result joins the results obtained by Itoga [16]. However Y. Choi [8] found that the predicted values are rather close to those of the experiment when we consider a $=$ Ry.

On the other hand, the difference obtained in our case between the predicted and the experimental fatigue limit is smaller than values obtained by Itoga and Choi $[16,8]$ which are important.

For the AISI 1045 carbon steel, the Murakami model [18] allowed us to estimate the fatigue limit of the test specimens without going through the fatigue tests which are very costly, just the determination of equivalent defect size and a simple measurement of the hardness will be sufficient.

This result will allow us to improve the fatigue performance of our mechanical parts while acting on surface roughness. The ideal is to be able to analytically determine the cutting conditions generating a part having a good fatigue lifetime. To do this, we could use our model expressing the roughness according to the cutting parameters that we had developed in a 
previous study [13]. Equation 4 express the model used which relates the roughness to the cutting parameters. Therefore, from this model, we could define the appropriate turning machining parameters to obtain the surface state required by the functionality of parts. Finally, through this model and the present study which partially predicts the fatigue limit, we can control the choice of machining parameters to obtain a part with a longer lifetime.

$$
\begin{aligned}
y= & b_{0}+\sum_{i=1}^{k} b_{i} \cdot x_{i}+\sum_{i=1}^{k-1} \sum_{j=i+1}^{k} b_{i j} \cdot x_{i} x_{j}+\sum_{i=1}^{k} b_{i i} \cdot x_{i}^{2}+\sum_{i=1}^{k-1} \sum_{j=i+1}^{k} b_{i j j} \cdot x_{i} \cdot x_{j}^{2}+\sum_{i=1}^{k-1} \sum_{j=i+1}^{k} b_{i i j} \cdot x_{i}^{2} \cdot x_{j} \\
& +\sum_{i=1}^{k-1} \sum_{j=i+1}^{k} b_{i i j j} \cdot x_{i}^{2} \cdot x_{j}^{2}
\end{aligned}
$$

with

$\mathrm{k}$ : number of factors, in our case $\mathrm{k}=3$.

$\mathrm{x}_{1}$ : tool nose radius $\mathrm{r} \varepsilon$,

$\mathrm{x}_{2}$ : feed rate $\mathrm{f}$

$\mathrm{x}_{3}$ : cutting speed Vc.

The coefficients $b_{i}, b_{i i}$, biij, $b_{i j j}$ and $b_{i i j j}$ are:

$$
\begin{array}{lllll}
\mathrm{b}_{0}=14.9 & \mathrm{~b}_{1}=8.717 & \mathrm{~b}_{2}=-275 & \mathrm{~b}_{3}=-0.2619 & \\
\mathrm{~b}_{11}=-2.286 & \mathrm{~b}_{12}=153.2 & \mathrm{~b}_{13}=-4206.10^{-5} & \mathrm{~b}_{22}=1006 & \mathrm{~b}_{23}=3.617 \\
\mathrm{~b}_{33}=1254.10^{-6} & \mathrm{~b}_{112}=-80.09 & \mathrm{~b}_{113}=-8399.10^{-6} & \mathrm{~b}_{122}=-872.9 & \mathrm{~b}_{133}=-4879.10^{-7} \\
\mathrm{~b}_{223}=-10.42 & \mathrm{~b}_{233}=-1463.10^{-5} & \mathrm{~b}_{1122}=442.4 & \mathrm{~b}_{1133}=3806.10^{-7} & \mathrm{~b}_{2233}=4214.10^{-5}
\end{array}
$$

\section{CONCLUSION}

$\mathrm{I}$ $\mathrm{n}$ this study, the adverse effect of the surface state on fatigue behavior of AISI1045 carbon steel were highlighted in the case of turning process. The fatigue resistance increases with the decrease of the surface roughness. In fact, the roughness is the series of geometric irregularities generating local stress concentrations and the crack initiation depends on the size of these irregularities.

Based on the S-N curves obtained from fatigue tests, it was noted that for a stress amplitude of $225 \mathrm{MPa}$, the fatigue lifetime went up from $2.10^{5}$ cycles for a surface roughness of $\mathrm{Ra}=3.12 \mu \mathrm{m}$ to $2.7510^{5}$ cycles in the case of $\mathrm{Ra}=2.26 \mu \mathrm{m}$, to 6.5 $10^{5}$ cycles for roughness of $\mathrm{Ra}=1.25 \mu \mathrm{m}$ and for a surface roughness of $0.5 \mu \mathrm{m}$ the number of cycles to failure reaches 1.6 $10^{6}$ cycles. Therefore, the fatigue lifetime increase with the decrease of surface roughness.

Actually, the fatigue resistance of mechanical parts could be improved by improving the surface roughness. To achieve this interesting result, the cutting parameters should be controlled. In our case, a mathematical model were proposed that express surface roughness function of the cutting parameters.

Besides this results, the fatigue limit were predicted considering the surface roughness defect. The model adopted present an interesting results as compared with experimental data.

\section{REFERENCES}

[1] Novovic, D. Dewes, R. C. Aspinwall, D. K. Voice, W. and Bowen, P. (2004). The effect of machined topography and integrity on fatigue life, International Journal of Machine Tools \& Manufacture, 44, pp. 125-134.

DOI:10.1016/j.ijmachtools.2003.10.018.

[2] Campbell, F. C. (2008). Elements of Metallurgy and Engineering Alloys, ASM International. pp. 243-263.

[3] Ming, Z. Weiqiang, W, Pengfei, W. Yan, L and Jianfeng Li. (2016). The fatigue behavior and mechanism of FV520B-I with large surface roughness in a very high cycle regime. Engineering Failure Analysis, 66, pp. 432-444. DOI: $10.1016 /$ j.engfailanal.2016.04.029.

[4] Suraratchai, M. Limido, J. Mabru, C. and Chieragatti, R.. (2008). Modelling the influence of machined surface roughness on the fatigue life of aluminium alloy, International Journal of Fatigue, 30, pp. 2119-2126. 
DOI:10.1016/j.ijfatigue.2008.06.003.

[5] Guoliang, L. Chuanzhen, H. Bin, Z Xiangyu, W. and Zhanqiang, L. (2016). Surface integrity and fatigue performance of 17-4PH stainless steel after cutting operations, Surface \& Coatings Technology, 307, pp. 182-189. DOI:10.1016/j.surfcoat.2016.08.086.

[6] Suraratchaï, M. Mabru, C. Chieragatti, R. and Rezai Aria, F. (2005). Influence de gammes d'usinage sur la tenue en fatigue d'un alliage léger aéronautique, 17ème Congrès Français de Mécanique. Troyes, France. https://www.researchgate.net/publication/27811748_Influence_de_gammes_d'usinage_sur_la_tenue_en_fatigue_d'u n_alliage_leger_aeronautique.

[7] Alang, N.A. Razak, N.A. and K.Miska, A. (2011). Effect of Surface Roughness on Fatigue Life of Notched Carbon Steel, International Journal of Engineering \& Technology, 11, pp. 160-163. http://www.ijens.org/Vol\%2011\%20I\%2001/119101-2727\%20IJET-IJENS.pdf.

[8] Youngsik, C. (2015). Influence of feed rate on surface integrity and fatigue performance of machined surfaces, International Journal of Fatigue, 78, pp. 46-52. DOI: 10.1016/j.ijfatigue.2015.03.028.

[9] Kimakh, K. Aghzer, S. Chouaf, A. Saoud, A. Mallil E. H. and Chergui, M. (2018). Improvement of fatigue life of AISI 1045 carbon steel of parts obtained by turning process through feed rate, Procedia Structural Integrity, 9, pp. 243-249. DOI: $10.1016 /$ j.prostr.2018.06.039.

[10] Davies, D. P. Jenkinsa, S. L. and Legga, S. J. (2014). The Effect Machining Processes can have on the Fatigue Life and Surface Integrity of Critical Helicopter Components. Procedia CIRP 13. PP. 25-30. DOI: 10.1016/j.procir.2014.04.005.

[11]Javidi, A. Rieger, U. and Eichlseder, W. (2008). The effect of machining on the surface integrity and fatigue life, International Journal of fatigue, 30, pp. 2050-2055. DOI: 10.1016/j.ijfatigue.2008.01.005.

[12] E8/E8M-13a. Standard Test Methods for Tension Testing of Metallic Materials, ASTM, 2013.

[13] E466-07. Standard Practice for Conducting Force Controlled Constant Amplitude Axial, ASTM, 2007.

[14] Kimakh, K. Aghzer, S. Chouaf, A. Saoud, A. Mallil E. H. and Chergui, M. (2018). Analytical model for predicting surface roughness as a function of aisi 1045 steel machining parameters, International Journal of Modern Manufacturing Technologies, 10, pp. 50-56. http://www.ijmmt.ro/vol10no12018/08_Khadija_Kimakh.pdf.

[15] ISO4288. Spécification géométrique des produits (GPS) -- État de surface: Méthode du profil -- Règles et procédures pour l'évaluation de l'état de surface,ISO, 1996.

[16] Bagehorn, S. Wehr, J and Maier, H. J. (2017). Application of mechanical surface finishing processes for roughness reduction and fatigue improvement of additively manufactured Ti-6Al-4V parts, International Journal of Fatigue, 102. pp. 135-142. DOI: 10.1016/j.ijfatigue.2017.05.008.

[17] Itoga, H. Tokaji, K. Nakajima, M. and Ko, H. N. (2003). Effect of surface roughness on step-wise S-N characteristics in high strength steel, International Journal of Fatigue, 25, pp. 379-385. DOI: 10.1016/S0142-1123(02)00166-4.

[18] J. Wang, Y. Zhang, Q, Sun, S. Liu, B, Shi and H. Lu. (2016). Giga-Fatigue Life Prediction of FV520B-I with Surface, Materials \& Design, 89. pp. 1028-1034. DOI: 10.1016/j.matdes.2015.10.104.

[19] Murakami, Y. (2002). Metal Fatigue: Effects of Small Defects and Nonmetallic Inclusion, Oxford, Elsevier. DOI:10.1016/B978-0-08-044064-4.X5000-2

\section{NOMENClATURE}

$\begin{array}{ll}\mathrm{S}_{\mathrm{Y} 02} & \text { Offset yield stress } \\ \mathrm{S}_{\mathrm{UTS}} & \text { Ultimate tensile stress } \\ \mathrm{A} & \text { Elongation } \\ \mathrm{E} & \text { Elasticity modulus } \\ H V & \text { Vickers hardness } \\ \lambda c & \text { Cut-off } \\ \mathrm{R} a & \text { Arithmetical mean height } \\ \mathrm{Ry} & \text { Maximum Height of the Profile } \\ \mathrm{N} & \text { Spindle speed } \\ f & \text { Feed rate }\end{array}$




\begin{tabular}{ll}
\hline$a p$ & Depth of cut \\
$r \varepsilon$ & Tool nose radius \\
$l_{\text {defect }}$ & Width of the streak \\
$r_{Z P L}$ & Radius of the crack propagation area \\
$N_{f}$ & Number of cycles to failure \\
$R$ & Stress ratio \\
$S_{\max }$ & Maximal stress \\
$S_{\min }$ & Minimal stress \\
$\sigma_{w}$ & Fatigue limit \\
$\sqrt{\text { area }}$ & Equivalent defect size
\end{tabular}

